\title{
Preoperative neutrophil-lymphocyte ratio and CEA is associated with poor prognosis in patients with synchronous colorectal cancer liver metastasis
}

\author{
Hyunjung Kim ${ }^{1, *}$, Hae II Jung, ${ }^{1, *}$, Soon Ha Kwon', Sang Ho Bae', Hyung Chul Kim², Moo-Jun Baek, \\ Moon Soo Lee ${ }^{1}$ \\ ${ }^{1}$ Department of Surgery, Soonchunhyang University Cheonan Hospital, Cheonan, Korea \\ ${ }^{2}$ Department of Surgery, Soonchunhyang University Bucheon Hospital, Bucheon, Korea
}

\begin{abstract}
Purpose: Recently, the neutrophil-to-lymphocyte ratio (NLR), an inflammatory response marker, has been reported to be associated with the prognosis in patients with various type of cancer. However, there have been no studies until now that have explored the prognostic role of combined detection of NLR and CEA in patients with synchronous liver-limited colorectal metastases (sCRLM).

Methods: Eighty-three patients who histologically diagnosed as SCRLM were selected. Their laboratory and clinical data were collected retrospectively. Using receiver operating characteristic curve analysis, the cutoff value of NLR was calculated based on which patients were assigned to a high NLR (more than 1.94) group and low NLR (less than 1.94) group. A cutoff value of $100 \mathrm{ng} / \mathrm{mL}$ for serum CEA level was used in light of the previous literature.

Results: CEA level and Poorly differentiated histology of colon cancer was significantly correlated with high NLR (P = 0.005 and $P=0.048$, respectively). The multivariate analysis identified the high NLR as independent prognostic factors for OS and DFS in all patients ( $P=0.010$ and $P=0.006$, respectively). Patients with both low levels of NLR and CEA had a significantly longer $\mathrm{OS}$ and $\mathrm{DFS}(\mathrm{P}=0.026$ and $\mathrm{P}=0.009$, respectively).

Conclusion: In conclusion, elevated preoperative NLR is strongly correlated with both survival and recurrence in patients who have been diagnosed with resectable SCRLM. The combination of NLR and CEA level could be a more powerful prognostic marker than NLR alone.

[Ann Surg Treat Res 2019;96(4):191-200]
\end{abstract}

Key Words: Colonic neoplasms, Liver, Metastasis, Neutrophils, Carinoembryonic antigen, Prognosis

\section{INTRODUCTION}

Colorectal cancer (CRC) is now the fifth most common malignancy in men, the fourth most common in women, and the fifth most common cause of death from cancer in Korea [1]. The liver is the most common site for CRC metastases, because of the enteric venous drainage via the portal circulation. Up to $50 \%$ of CRC patients develop liver metastases, and $25 \%$ of patients with newly diagnosed CRC already have metastases. Furthermore, the liver is the sole site of metastasis in $35 \%$ of cases. Several studies have shown that $10 \%$ to $30 \%$ of patients with synchronous liver-limited colorectal metastases (SCRLM) have potentially resectable disease at the point of detection and can be treated surgically [2]. Surgical resection of hepatic metastases has been shown to significantly improve survival, with reported 5 -year survival rates of $30 \%-40 \%$ in some centers.
Received May 28, 2018, Revised July 18, 2018, Accepted August 3, 2018

\section{Corresponding Author: Moon Soo Lee}

Department of Surgery, Soonchunhyang University Cheonan Hospital, 31 Suncheonhyang 6-gil, Dongnam-gu, Cheonan 31151, Korea

Tel: +82-41-570-3635, Fax: +82-41-571-0129

E-mail: gs2834@schmc.ac.kr

ORCID code: https://orcid.org/0000-0002-3955-1331
*Hyunjung Kim and Hae II Jung contributed equally to this study as cofirst authors.

Copyright (C) 2019, the Korean Surgical Society

(c) Annals of Surgical Treatment and Research is an Open Access Journal. All articles are distributed under the terms of the Creative Commons Attribution NonCommercial License (http://creativecommons.org/licenses/by-nc/4.0/) which permits unrestricted non-commercial use, distribution, and reproduction in any medium, provided the original work is properly cited. 
Recent advances in surgical technique for partial hepatectomy, indications for liver resection, imaging modalities, and perioperative neoadjuvant chemotherapy, have increased the number of patients suitable for simultaneous surgical resection [3,4]. However, hepatic tumor recurrence rates remain high, at around $60 \%-65 \%$. Therefore, identifying patients who are more likely to have recurrence after surgery is important for guiding treatment.

Recently, it has been shown that the inflammatory response (IR) plays a key role in the survival of cancer patients. The neutrophil-to-lymphocyte ratio (NLR), an IR marker, has been reported to be associated with patients' prognosis for various types of cancer, including breast [5] stomach [6], pancreatic [7], and hepatocellular carcinoma [8]. Several recent studies have reported on the role of NLR as a prognostic factor for CRC patients [9]. Moreover, NLR is also a predictor in CRLM after surgery [10]. However, few studies have investigated the prognostic value of NLR in resectable SCRLM.

Serum CEA is an adhesion molecule of the immunoglobulin cell and is known to be increased in several cancers, including CRC [11]. CEA is also widely accepted as a clinically significant prognostic indicator for both recurrence and therapeutic benefit in CRC [12]. CEA mediates metastasis and IRs by binding to its receptor, hnRNP, in the liver [13]. One study on the correlation between CEA and colorectal metastasis found that CEA was associated with higher liver metastasis but not with other organ metastasis or nonmetastatic CRC [14]. However, the prognostic value of CEA in CRC with liver metastasis remains uncertain. A meta-analysis showed that low preoperative CEA level (less than $50 \mathrm{ng} / \mathrm{mL}$ ) was associated with a significantly better survival time following liver metastasis resection. Another meta-analysis using a cut-off of $200 \mathrm{ng} / \mathrm{mL}$ to stratify the 2 groups, also demonstrated improved survival time with lower CEA level [15].

There have been no studies until now that have explored the prognostic role of combined detection of preoperative NLR and CEA levels in patients with sCRLM. Therefore, the aim of this study was to evaluate each prognostic utility of preoperative NLR or CEA levels in patients undergoing simultaneous surgery for SCRLM, and was to determines the predictive ability of combining of preoperative NLR and CEA levels in SCRLM patients.

\section{METHODS}

\section{Patient selection}

Eighty-three patients were selected by the following inclusion criteria: patients who (1) were histologically diagnosed as CRLM at the Soonchunhyang University Cheonan and Bucheon Hospital between 2005 and 2015, (2) were initially diagnosed as colon cancer with liver metastasis, (3) had undergone radical resection for colon cancer and hepatic metastases synchronously, (4) had negative surgical margin, (5) were received adjuvant chemotherapy, (6) had available

Table 1. Baseline characteristics of patients $(n=83)$

\begin{tabular}{|c|c|}
\hline Characteristic & Value \\
\hline \multicolumn{2}{|l|}{ Sex } \\
\hline Male & $62(74.7)$ \\
\hline Female & $21(25.3)$ \\
\hline Age (yr) & $59.5 \pm 10.0$ \\
\hline \multicolumn{2}{|l|}{ CRC operation } \\
\hline Right hemicolectomy & $16(19.3)$ \\
\hline Left hemicolectomy & $4(4.8)$ \\
\hline Anterior resection & $30(36.1)$ \\
\hline Low anterior resection & $29(34.9)$ \\
\hline Abdominoperineal resection & $4(4.8)$ \\
\hline \multicolumn{2}{|l|}{ Neoadjuvant chemotherapy } \\
\hline Yes & $24(28.9)$ \\
\hline No & $58(69.9)$ \\
\hline No. of liver metastasis & $1.49(1.0-3.0)$ \\
\hline \multicolumn{2}{|l|}{ Hepatectomy } \\
\hline Major & $39(47.0)$ \\
\hline Minor & $44(53.0)$ \\
\hline \multicolumn{2}{|l|}{ CRC T stage } \\
\hline $\mathrm{T} 3$ & $62(74.7)$ \\
\hline $\mathrm{T} 4$ & $19(22.9)$ \\
\hline \multicolumn{2}{|l|}{ CRC histology } \\
\hline Well differentiated & $4(4.8)$ \\
\hline Moderate differentiated & $68(9.5)$ \\
\hline Poorly differentiated & $11(13.3)$ \\
\hline \multicolumn{2}{|l|}{ CRC $N$ stage } \\
\hline NO & $16(19.3)$ \\
\hline N1 & $38(45.8)$ \\
\hline N2 & $27(32.5)$ \\
\hline \multicolumn{2}{|l|}{ CRC microvascular invasion } \\
\hline Yes & $26(31.3)$ \\
\hline No & $52(62.7)$ \\
\hline \multicolumn{2}{|l|}{ Inflammatory related complication } \\
\hline Colon anastomosis leakage & $2(9.5)$ \\
\hline Hepatectomy site leakage & $4(19.0)$ \\
\hline Wound complication & $7(33.3)$ \\
\hline Other & $8(38.1)$ \\
\hline $\mathrm{CEA}(\mathrm{ng} / \mathrm{mL})$ & $11.1(3.8-107.5)$ \\
\hline CA 19-9 (ng/mL) & $21.3(4.8-172.0)$ \\
\hline $\mathrm{a}-\mathrm{FP}(\mathrm{ng} / \mathrm{mL})$ & $2.5(1.9-5.2)$ \\
\hline Albumin (mg/L) & $3.9(2.5-5.0)$ \\
\hline Total bilirubin ( $\mu \mathrm{mol} / \mathrm{L})$ & $0.4(0.3-0.8)$ \\
\hline WBC count $\left(\times 10^{3} / \mu \mathrm{L}\right)$ & $7.8(5.6-10.7)$ \\
\hline Neutrophil count $\left(\times 10^{9} / \mathrm{L}\right)$ & $4.9(2.8-8.0)$ \\
\hline Lymphocyte count $\left(\times 10^{9} / \mathrm{L}\right)$ & $24.3(12.1-36.3)$ \\
\hline Platelet count $\left(\times 10^{9} / \mathrm{L}\right)$ & $269.7(191.5-374.5)$ \\
\hline Length of stay & $21.5(13.5-31.5)$ \\
\hline
\end{tabular}

Values are presented as number $(\%)$, mean \pm standard deviation, or median (interquartile range).

CRC, colorectal cancer. 
records of blood chemistry and CEA, and (7) had available follow-up information. The exclusion criteria were patients who had clinical evidence of infection, other metastasis prior to surgery, or evidence of hematological disease, such as lymphoma and leukemia. The Institutional Review Board of the Soonchunhyang University Cheonan and Bucheon Hospital approved the study (SCHCA 2018-05-021). Written informed consent was waived by the IRB.

Table 2. Characteristics of the 83 patients grouped by NLR

\begin{tabular}{|c|c|c|c|}
\hline \multirow{2}{*}{ Characteristic } & \multirow{2}{*}{$\begin{array}{c}\text { Low NLR group } \\
\text { NLR }<1.94(n=42)\end{array}$} & \multirow{2}{*}{$\begin{array}{c}\text { High NLR group } \\
\text { NLR } \geq 1.94(n=41)\end{array}$} & \multirow{2}{*}{ P-value } \\
\hline & & & \\
\hline \multicolumn{4}{|l|}{ Sex } \\
\hline Male & $31(73.8)$ & $31(75.6)$ & 0.850 \\
\hline Female & $11(26.2)$ & $10(24.4)$ & \\
\hline Age $(y r)$ & $59.4 \pm 10.2$ & $59.6 \pm 11.8$ & 0.933 \\
\hline \multicolumn{4}{|l|}{ Neoadjuvant chemotherapy } \\
\hline Yes & $10(24.4)$ & $14(34.1)$ & 0.332 \\
\hline No & $31(75.6)$ & $27(65.9)$ & \\
\hline \multicolumn{4}{|l|}{ CRC operation } \\
\hline Right hemicolectomy & $6(14.3)$ & $10(24.4)$ & 0.399 \\
\hline Left hemicolectomy & $2(4.8)$ & $2(4.9)$ & \\
\hline Anterior resection & $13(31.0)$ & $17(41.5)$ & \\
\hline Low anterior resection & $18(42.9)$ & $11(26.8)$ & \\
\hline Abdominoperineal resection & $3(7.1)$ & $1(2.4)$ & \\
\hline \multicolumn{4}{|l|}{ CRC T stage } \\
\hline $\mathrm{T} 3$ & $31(77.5)$ & $31(75.6)$ & 0.841 \\
\hline $\mathrm{T} 4$ & $9(22.5)$ & $10(24.4)$ & \\
\hline \multicolumn{4}{|l|}{ CRC $N$ stage } \\
\hline No & $6(15.0)$ & $10(24.4)$ & 0.617 \\
\hline N1 & $20(50.0)$ & $18(43.9)$ & \\
\hline $\mathrm{N} 2$ & $14(35.0)$ & $13(31.7)$ & \\
\hline \multicolumn{4}{|l|}{ CRC histology } \\
\hline Well to moderate differentiated & $38(95.0)$ & $32(78.0)$ & 0.048 \\
\hline Poorly differentiated & $2(5.0)$ & $9(22.0)$ & \\
\hline \multicolumn{4}{|l|}{ CRC Microvascular invasion } \\
\hline Yes & $12(30.8)$ & $14(35.9)$ & 0.631 \\
\hline No & $27(69.2)$ & $25(64.1)$ & \\
\hline No. of liver metastasis & $1.0(1.0-3.0)$ & $2.0(1.0-2.5)$ & 0.562 \\
\hline \multicolumn{4}{|l|}{ Hepatectomy } \\
\hline Major & $18(42.9)$ & $21(51.2)$ & 0.445 \\
\hline Minor & $24(57.1)$ & $20(48.8)$ & \\
\hline \multicolumn{4}{|l|}{ Liver metastasis site } \\
\hline Unilobar & $29(69.0)$ & $29(70.7)$ & 0.867 \\
\hline Bilobar & $13(31.0)$ & $12(29.3)$ & \\
\hline \multicolumn{4}{|l|}{ Inflammatory complication } \\
\hline Yes & $9(21.4)$ & $12(29.3)$ & 0.411 \\
\hline No & $33(78.6)$ & $29(70.7)$ & \\
\hline Length of stay (day) & $18.0(13.5-22.5)$ & $25.0(17.0-31.5)$ & 0.013 \\
\hline \multicolumn{4}{|l|}{ CEA100 (ng/mL) } \\
\hline$<100$ & $39(92.9)$ & $28(68.3)$ & 0.005 \\
\hline$\geq 100$ & $9(7.1)$ & $13(31.7)$ & \\
\hline
\end{tabular}

Values are presented as number $(\%)$, mean \pm standard deviation, or median (interquartile range).

NLR, neutrophil-to-lymphocyte ratio; CRC, colorectal cancer. 
Table 3. Univariate and multivariate analysis for risk factors for overall survival

\begin{tabular}{|c|c|c|c|c|c|c|}
\hline \multirow{2}{*}{ Characteristic } & \multicolumn{3}{|c|}{ Univariate analysis } & \multicolumn{3}{|c|}{ Multivariate analysis } \\
\hline & $\mathrm{HR}$ & $95 \% \mathrm{Cl}$ & P-value & $\mathrm{HR}$ & $95 \% \mathrm{Cl}$ & P-value \\
\hline \multicolumn{7}{|l|}{ Sex } \\
\hline Male & 1.410 & $0.610-3.259$ & 0.422 & & & \\
\hline Female & Ref & & & & & \\
\hline Age & 0.998 & $0.965-1.032$ & 0.898 & & & \\
\hline \multicolumn{7}{|l|}{ Liver metastasis number } \\
\hline$\leq 3$ & Ref & & & Ref & & \\
\hline$>3$ & 2.851 & $1.343-6.052$ & 0.006 & 1.970 & $0.863-4.496$ & 0.107 \\
\hline No. of liver metastasis & 1.182 & $1.055-1.324$ & 0.004 & & & \\
\hline \multicolumn{7}{|l|}{ Hepatectomy } \\
\hline Major & 1.215 & $0.613-2.408$ & 0.577 & & & \\
\hline Minor & Ref & & & & & \\
\hline \multicolumn{7}{|l|}{ CRC T stage } \\
\hline $\mathrm{T} 3$ & Ref & & & & & \\
\hline $\mathrm{T} 4$ & 2.847 & $1.303-6.219$ & 0.009 & & & \\
\hline \multicolumn{7}{|l|}{ CRC histology } \\
\hline Well to moderate differentiated & Ref & & & & & \\
\hline Poorly differentiated & 0.496 & $0.208-1.181$ & 0.113 & & & \\
\hline \multicolumn{7}{|l|}{ CRC LN metastasis } \\
\hline Yes & 3.394 & $1.036-11.119$ & 0.044 & 3.582 & $1.079-11.891$ & 0.037 \\
\hline No & Ref & & & Ref & & \\
\hline \multicolumn{7}{|l|}{ CRC microvascular invasion } \\
\hline Yes & 1.996 & $0.972-4.099$ & 0.049 & & & \\
\hline No & Ref & & & & & \\
\hline \multicolumn{7}{|l|}{ Neoadjuvant chemotherpy } \\
\hline Yes & 1.735 & $0.862-3.494$ & 0.123 & & & \\
\hline No & Ref & & & & & \\
\hline \multicolumn{7}{|l|}{ Inflammatory complication } \\
\hline Yes & 3.904 & $1.981-7.694$ & $<0.001$ & 3.722 & $1.867-7.419$ & 0.000 \\
\hline No & Ref & & & Ref & & \\
\hline \multicolumn{7}{|l|}{ Clavien-Dindo classification grade } \\
\hline I & Ref & & & & & \\
\hline II & 1.680 & $0.720-3.925$ & 0.230 & & & \\
\hline III & 10.258 & $3.814-27.591$ & $<0.001$ & & & \\
\hline IV & 128.885 & $18.833-882.010$ & $<0.001$ & & & \\
\hline Length of stay & 1.013 & $1.004-1.021$ & 0.005 & & & \\
\hline \multicolumn{7}{|l|}{$\mathrm{CEA}(\mathrm{ng} / \mathrm{mL})$} \\
\hline$<100$ & Ref & & & Ref & & \\
\hline$\geq 100$ & 2.098 & $1.022-4.305$ & 0.043 & 1.207 & $0.512-2.845$ & 0.048 \\
\hline CA 19-9 & 1.000 & $1.000-1.000$ & 0.026 & & & \\
\hline a-FP & 0.977 & $0.867-1.102$ & 0.710 & & & \\
\hline \multicolumn{7}{|l|}{ NLR } \\
\hline$<1.94$ & Ref & & & Ref & & \\
\hline$\geq 1.94$ & 2.164 & $1.054-4.444$ & 0.035 & 2.636 & $1.266-5.489$ & 0.010 \\
\hline \multicolumn{7}{|l|}{ Liver metastasis location } \\
\hline Unilobar & Ref & & & & & \\
\hline Bilobar & 1.29 & $0.637-2.613$ & 0.480 & & & \\
\hline
\end{tabular}


Table 3. Continued

\begin{tabular}{|c|c|c|c|c|c|c|}
\hline \multirow{2}{*}{ Characteristic } & \multicolumn{3}{|c|}{ Univariate analysis } & \multicolumn{3}{|c|}{ Multivariate analysis } \\
\hline & HR & $95 \% \mathrm{Cl}$ & P-value & $\mathrm{HR}$ & $95 \% \mathrm{Cl}$ & P-value \\
\hline \multicolumn{7}{|l|}{ Liver resection margin } \\
\hline Negative & Ref & & & & & \\
\hline Positive & 2.103 & $0.862-5.132$ & 0.102 & & & \\
\hline
\end{tabular}

$\mathrm{HR}$, hazard ratio; $\mathrm{Cl}$, confidence interval; CRC, colorectal cancer; LN, lymph node; NLR, neutrophil-to-lymphocyte ratio.

\section{Clinical parameters and laboratory measurement of neutrophils, lymphocytes, and CEA}

Laboratory results including neutrophil count, lymphocyte count, and CEA were measured within 1 week prior to surgery as part of the routine workup. Eligible patients' clinical data including age, sex, cancer site, tumor stage, pathological class, differentiation, number of liver metastasis, and treatment type were collected from medical records.

\section{Calculation of NLR and CEA}

NLR was defined as the neutrophil to lymphocyte ratio. Using receiver operating characteristic curve analysis, the cutoff value for NLR was calculated based on which patients were assigned to a high NLR group (more than 1.94) or low NLR group (less than 1.94). A cutoff value of 100 for serum CEA level was used in the light of previous CEA study [15].

\section{Patient follow-up and statistical methods}

Synchronously detected liver metastases were defined as metastases detected prior to resection of the colon cancer and as having resection of CRLM within 12 weeks of surgery for the primary tumor. All patients were considered for adjuvant chemotherapy after surgery at our multidisciplinary team meeting, with 5-fluorouracil plus leucovorin $(\mathrm{n}=6)$, FOLFOX $(\mathrm{n}=32)$, FOLFOX plus bevacizumab $(\mathrm{n}=2)$, FOLFIRI $(\mathrm{n}=30)$, FOLFIRI plus bevacizumab $(n=8)$, or FOLFIRI plus cetuximab $(\mathrm{n}=5)$ regimen. And 24 patients were received neoadjuvant chemotherapy with FOLFOX ( $n=5)$, FOLFOX plus bevacizumab $(n=2)$, FOLFIRI $(n=2)$, FOLFIRI plus cetuximab $(n=6)$, and concurrent chemoradiotherapy $(\mathrm{n}=9)$ ). Overall survival (OS) was defined as the time from the first treatment (surgery or neoadjuvant chemotherapy) to the date of death. Disease-free survival (DFS) was defined as the time from the hepatic surgery to the date of the first local, regional, or metastatic recurrence. Follow-up and survival times were recorded in months. The statistical analysis was performed with IBM SPSS Statistics ver. 21.0 (IBM Co., Armonk, NY, USA). The comparison of categorical variables was performed by chi-square and Fisher exact tests. Continuous data were analyzed by Student t-test and MannWhitney U-test. Kaplan-Meier survival curves were used to analyze patients' overall and DFS. A Cox regression analysis was then done as a multivariable analysis of clinicopathological factors that affect both OS and DFS. All confidence intervals are $95 \%$.

\section{RESULTS}

\section{Patients and tumor characteristics}

Table 1 shows the clinicopathologic features and laboratory data of all patients $(n=83)$. Of these patients, $62(74.7 \%)$ were males and 21 (25.3\%) females. The mean age of patients was 59.5 years. All patients underwent liver resection. A total of 39 patients (47\%) had a "major" (three or more Couinaud segments) resection performed.

\section{Correlations of NLR and clinicopathological factors}

All clinicopathologic characteristics were comparable between patients grouped by NLR, as shown in Table 2. Poorly differentiated histology of colon cancer was significantly correlated with high NLR $(P=0.048)$, and a significant difference in CEA level (cutoff $100 \mathrm{ng} / \mathrm{mL}$ ) and length of stay was noted between groups ( $\mathrm{P}=0.005$ and $\mathrm{P}=0.013$, respectively). No statistically significant differences were noted between groups based on the type of colon operation, number of liver metastases, or type of hepatectomy.

\section{Correlation of clinicopathological factors with OS and DFS}

Univariate analysis revealed that the number of liver metastases (>3), T4 stage, lymph node metastasis, inflammatory complication, Clavien-Dindo classification grade, CEA $>100$ $\mathrm{ng} / \mathrm{mL}$, and high NLR were poor prognostic factors for OS in all patients $(\mathrm{P}=0.006, \mathrm{P}=0.009, \mathrm{P}=0.044, \mathrm{P}<0.001, \mathrm{P}<$ $0.001, P=0.043$, and $P=0.035$, respectively). And lymphnode metastasis, inflammatory complication, CEA level, and high NLR as independent prognostic factors for OS in multivariate analysis $(\mathrm{P}=0.037, \mathrm{P}<0.001, \mathrm{P}=0.048, \mathrm{P}=0.010$, respectively). The number of liver metastases $(>3)$, methods of hepatectomy (major or minor), lymph node metastasis, inflammatory complication, CA 19-9, and high NLR were poor prognostic factors for DFS in all patients in univariate analysis $(\mathrm{P}=0.016, \mathrm{P}=0.017, \mathrm{P}=0.040, \mathrm{P}=0.009, \mathrm{P}<0.013$, 
Table 4. Univariate and multivariate analysis for risk factors for recurrence

\begin{tabular}{|c|c|c|c|c|c|c|}
\hline \multirow{2}{*}{ Characteristic } & \multicolumn{3}{|c|}{ Univariate analysis } & \multicolumn{3}{|c|}{ Multivariate analysis } \\
\hline & $\mathrm{HR}$ & $95 \% \mathrm{Cl}$ & P-value & $\mathrm{HR}$ & $95 \% \mathrm{Cl}$ & P-value \\
\hline \multicolumn{7}{|l|}{ Sex } \\
\hline Male & 1.418 & $0.741-2.714$ & 0.291 & & & \\
\hline Female & Ref & & & & & \\
\hline Age & 0.995 & $0.968-1.022$ & 0.692 & & & \\
\hline \multicolumn{7}{|l|}{ Liver metastasis number } \\
\hline$\leq 3$ & Ref & & & Ref & & \\
\hline$>3$ & 2.324 & $1.170-4.617$ & 0.016 & 1.368 & $0.581-3.224$ & 0.473 \\
\hline No. of liver metastasis & 1.190 & $1.063-1.332$ & 0.003 & & & \\
\hline \multicolumn{7}{|l|}{ Hepatectomy } \\
\hline Major & 2.000 & $1.134-3.526$ & 0.017 & 1.795 & $0.995-3.238$ & 0.052 \\
\hline Minor & Ref & & & Ref & & \\
\hline \multicolumn{7}{|l|}{ CRC T stage } \\
\hline $\mathrm{T} 3$ & Ref & & & & & \\
\hline $\mathrm{T} 4$ & 1.777 & $0.921-3.428$ & 0.086 & & & \\
\hline \multicolumn{7}{|l|}{ CRC histology } \\
\hline Well to moderate differentiated & Ref & & & & & \\
\hline Poorly differentiated & 0.613 & $0.218-1.726$ & 0.394 & & & \\
\hline \multicolumn{7}{|l|}{ CRC LN metastasis } \\
\hline Yes & Ref & & & Ref & & \\
\hline No & 2.135 & $1.036-4.400$ & 0.040 & 2.415 & $1.149-5.078$ & 0.020 \\
\hline \multicolumn{7}{|l|}{ CRC microvascular invasion } \\
\hline Yes & 1.601 & $0.907-2.827$ & 0.105 & & & \\
\hline No & Ref & & & & & \\
\hline \multicolumn{7}{|l|}{ Neoadjuvant chemotherpy } \\
\hline Yes & 1.363 & $0.755-2.460$ & 0.304 & & & \\
\hline No & Ref & & & & & \\
\hline \multicolumn{7}{|l|}{ Inflammatory Complication } \\
\hline Yes & 2.212 & $1.215-4.026$ & 0.009 & 1.890 & $1.008-3.545$ & 0.047 \\
\hline No & Ref & & & Ref & & \\
\hline \multicolumn{7}{|l|}{ Clavien-Dindo classification grade } \\
\hline 1 & Ref & & & & & \\
\hline II & 1.126 & $0.616-2.060$ & 0.699 & & & \\
\hline III & 2.657 & $1.152-6.128$ & 0.022 & & & \\
\hline IV & 12.800 & $2.541-64.474$ & 0.002 & & & \\
\hline Length of stay & 1.009 & $1.000-1.018$ & 0.054 & & & \\
\hline \multicolumn{7}{|l|}{$\mathrm{CEA}(\mathrm{ng} / \mathrm{mL})$} \\
\hline$<100$ & Ref & & & Ref & & \\
\hline$\geq 100$ & 1.804 & $0.978-3.325$ & 0.059 & 1.446 & $0.730-2.865$ & 0.290 \\
\hline CA 19-9 & 1.000 & $1.000-1.000$ & 0.013 & & & \\
\hline $\mathrm{a}-\mathrm{FP}$ & 1.009 & $0.998-1.020$ & 0.126 & & & \\
\hline \multicolumn{7}{|l|}{ NLR } \\
\hline$<1.94$ & Ref & & & Ref & & \\
\hline$\geq 1.94$ & 1.841 & $1.056-3.211$ & 0.031 & 2.229 & $1.256-3.958$ & 0.006 \\
\hline \multicolumn{7}{|l|}{ Liver metastasis location } \\
\hline Unilobar & Ref & & & & & \\
\hline Bilobar & 1.198 & $0.666-2.158$ & 0.546 & & & \\
\hline
\end{tabular}


Table 4. Continued

\begin{tabular}{|c|c|c|c|c|c|c|}
\hline \multirow{2}{*}{ Characteristic } & \multicolumn{3}{|c|}{ Univariate analysis } & \multicolumn{3}{|c|}{ Multivariate analysis } \\
\hline & $\mathrm{HR}$ & $95 \% \mathrm{Cl}$ & P-value & $\mathrm{HR}$ & $95 \% \mathrm{Cl}$ & P-value \\
\hline \multicolumn{7}{|l|}{ Liver resection margin } \\
\hline Negative & Ref & & & Ref & & \\
\hline Positive & 2.105 & $0.934-4.741$ & 0.073 & 1.684 & $0.726-3.906$ & 0.225 \\
\hline
\end{tabular}

$\mathrm{HR}$, hazard ratio; $\mathrm{Cl}$, confidence interval; CRC, colorectal cancer; LN, lymph node; NLR, neutrophil-to-lymphocyte ratio.
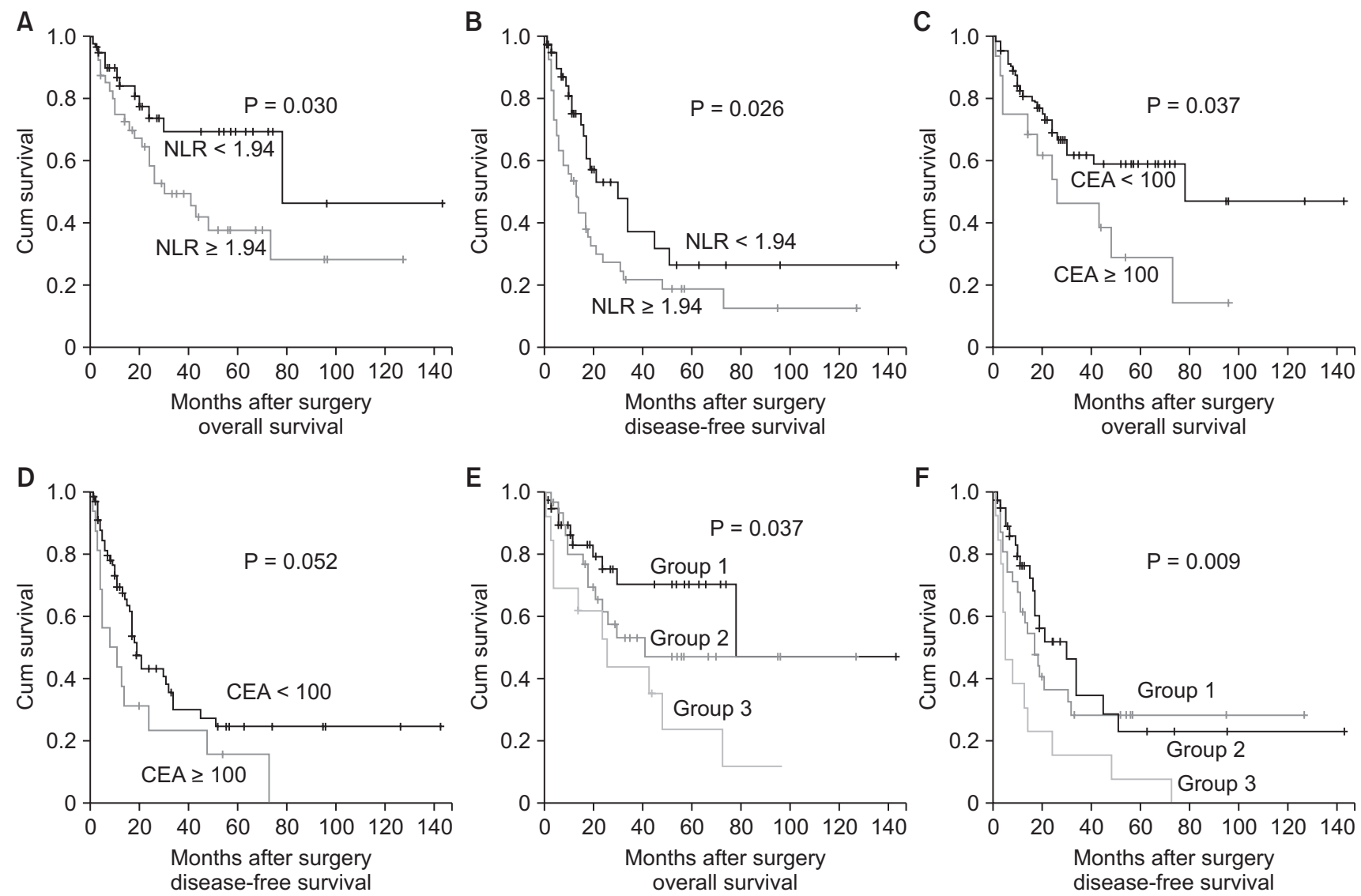

Fig. 1. Kaplan-Meier survival curves for overall survival (OS) and disease-free survival (DFS) in patients with synchronous liverlimited colorectal metastase according to their neutrophil-to-lymphocyte ratio (NLR) and CEA levels. (A) OS according to NLR, (B) DFS according to NLR, (C) OS according to CEA levels, (D) DFS according to CEA levels, (E) OS according to combination of NLR and CEA levels (group 1: both high, group 2: either high, group 3 both low), (F) DFS according to combination of NLR and CEA levels (group 1: both high, group 2: either high, group 3 both low).

and $\mathrm{P}=0.031$, respectively). And in multivariate analysis, lymph-node metastasis, inflammatory complication, and high NLR as independent prognostic factors for DFS in all patients ( $\mathrm{P}=0.020, \mathrm{P}=0.047$, and $\mathrm{P}=0.006$, respectively). The other clinicopathological parameters (age, sex, colon cancer histologic differentiation, microvascular invasion, location of liver metastasis, and type of hepatectomy) showed no correlation with the OS of patients with sCRLM (Tables 3, 4).

\section{Analysis of survival according to the NLR and CEA for sCRLM}

Survival rates were compared using the Kaplan-Meier method. The survival of patients with high NLR and CEA was significantly poorer than that of low NLR and CEA (log-rank test, $\mathrm{P}=0.030$ and $\mathrm{P}=0.037$, respectively). The recurrence rate with high NLR was also significantly higher than with low NLR ( $P=0.026)$ and also CEA level is expected to influence DFS $(P=0.052)$. We further divided patients into 3 groups according to their NLR and CEA levels. Patients with both levels 
low were assigned to group 1, both high were group 3, and the rest were group 2. Patients in group 1 had a significantly longer OS and DFS than group $3 \operatorname{did}(\mathrm{P}=0.026$ and $\mathrm{P}=0.009$, respectively) (Fig. 1).

\section{DISCUSSION}

Our study revealed that in combination high NLR and CEA levels might be an independent prognostic biomarker that correlates with survival and prognosis in patients with SCRLM. This is the first study evaluating the effectiveness of this metric in patients with resectable sCRLM. Since Walsh et al. [9] first reported that NLR was a prognostic indicator in patients with CRC, many studies have confirmed the correlation of NLR and prognosis [16-18]. However, only a few studies have reported that combining NLR and CEA levels correlated with prognosis in CRCM [19]. Moreover, most of the previous studies included patients at all stages of CRC or included inoperable stage IV CRC group [20]. Chiang et al. [18] demonstrated that NLR and CEA levels predict the survival of stage I-III CRC patients who received curative surgery. Zhan et al. [21] reported on combined detection of NLR and CEA as an independent prognostic factor in stage II and III CRC patients. Halazun et al. [16] documented that elevation of NLR predicts survival of patients who were included in both synchronous and metachronous groups for CRLM after hepatic resection. However, they only evaluated NLR by itself. Moreover, in metachronous liver metastasis, tumor biology could be changed due to primary tumor resection and adjuvant chemotherapy.

In the present study, colon cancer lymph-node metastasis, postoperative inflammatory complications, and high NLR were shown, when used independently, to be poor prognostic factors for both overall and recurrence-free survival in multivariate analysis. Previous commonly used clinicopathological factors, such as patient age, colon cancer location, T stage, microvascular invasion, and number of liver metastases showed no significant correlation with high NLR [2]. More aggressive histology and length of stay in hospital were significantly correlated with high NLR. Some studies also showed that histopathologic factors such as differentiation, angio-invasion, and tumor infiltrating inflammation of primary CRC and metastatic lesion were independent risk factor for recurrence after hepatic resection in CRLM [22]. These results suggest that elevated NLR and inflammatory complications have an important role in the aggressiveness of tumors.

Recently, inflammation as a protective response that paradoxically plays a critical role in tumor development has attracted great interest. One inflammatory marker, NLR, has been reported as a powerful index of the systemic IR. Because neutrophilia and lymphopenia occur during systemic inflammation, NLR is an important marker which represents a balance between pro-tumor inflammatory pathways and the immune systems antitumor functions. Increased NLR means that elevations in inflammatory cells, affect tumor growth in the microenvironment. Furthermore, they suppress cell-mediated immunity, thereby facilitating the immune escape of tumor cells [23]. High NLR is correlated with tumor invasiveness, angiogenesis and metastasis [24]. Elevated NLR was correlated with OS in several types of cancer including CRC [5-10].

Our study showed that inflammatory postoperative complications, such as anastomosis leakage and wound complication, are independent prognostic factors of survival and recurrence in multivariate analysis. Many studies have also reported a correlation between cancer-associated inflammation and survival and prognosis in various cancers, for which there are several possible explanations. Tumor-associated inflammation induces crosstalk between nonmalignant and malignant cells through mediators such as cytokines, chemokines, and prostaglandins. The tumor microenvironment under inflammatory conditions leads to tumor progression and metastasis, and this microenvironment provides a source of extracellular matrix-modifying enzymes that facilitate angiogenesis, invasion, and metastasis [25]. Major host cell types involved in inflammation are macrophages, myeloid cells, lymphocytes, and mesenchymal cells. Neutrophils may also contribute to progression and dissemination of cancer with a number of studies suggesting an important role. Neutrophil extracellular trap (NET) are networks of extracellular DNA derived from neutrophils. They trap circulating tumoral cells and subsequently increase the mature metastatic-disease burden. Studies have shown that NET products in vitro are increased in CRC patients [26]. Human neutrophil peptides-1, -2 , and -3 (HNP 1, -2, and -3) were upregulated in CRC patients when compared to normal colon tissue. HNP levels can be applied as important markers in patients with lymph node or liver metastasis [27]. Neutrophils induce granulocyte-colony stimulating factor release from tumor cells through the release of interleukin (IL)-1 and tumor necrosis factor (TNF)-alpha. Neutrophilia increases inflammatory markers, such as vascular endothelial growth factor, CXCL8, proteases (metalloproteinase tissue inhibitors), and antiapoptotic markers (nuclear factorkappa B [NF-kB]), which are associated with tumor growth and progression [25]. Chronic inflammation plays an important role in the proliferation and metastasis of tumor cells. In addition, many studies suggest that cancer-associated inflammation affects cancer development and progression. Transcription factors, including NF- $\mathrm{B}$ and STAT3, and inflammatory cytokines, such as IL-1 $\beta$, IL-6, IL-23, and TNF- $\alpha$, are associated with cancer-related inflammation. Further supporting the link, some studies have shown that COX-2 inhibitors and nonsteroidal anti-inflammatory drugs reduce not only CRC 
incidence but also metastasis and overall mortality [28].

In our study, high CEA showed a strong trend with lower OS and DFS in univariate analysis. CEA is also a widely accepted prognostic indicator of therapeutic response and monitoring of recurrence in CRC, and the CEA level is recommended as a gold standard for follow-up by the American Society of Clinical Oncology and European Society for Medical Oncology [29,30]. However, in CRC with liver metastasis, especially resectable sCRLM, the value of CEA has been less well understood. Some reports showed low CEA levels (less than $200 \mathrm{ng} / \mathrm{mL}$ ) were correlated with better survival. They reported a 5-year survival of $48.9 \%$, compared to $0 \%$ for high CEA levels. A previous metaanalysis demonstrated that preoperative CEA level less than 50 $\mathrm{ng} / \mathrm{mL}$ was associated with better survival after liver resection [15]. Although the optimal cutoff value remains uncertain, (many studies have used cutoff values ranging from 20 to 200 $\mathrm{ng} / \mathrm{mL}) 100 \mathrm{ng} / \mathrm{mL}$ was used in this study. We have also shown that, compared to patients with lower NLR, patients with high NLR were significantly correlated with high CEA levels measured at the preoperational stage (CEA $<100$ or $>100 \mathrm{ng}$ / $\mathrm{mL})$. As shown in Fig. 1, the CEA level was correlated with OS and DFS, and the combination of NLR and CEA was a better prognosticator for resectable sCRLM patients than NLR or CEA alone. There are several advantages to the use of serum NLR and CEA levels, because they are easily measured in blood test and routinely checked in all CRC patients. The combination of NLR and CEA not only reflects the tumor characteristics, but also represents the inflammatory and immune status of tumors. Zhan et al. [21] also demonstrated that COCN (combination of CEA and NLR) is a more powerful independent predictor than NLR or CEA alone in patients with stage II or III CRC.

Our study has several limitations. First, although patients were selected only if they had resectable sCRLM, because of working within a single institution and using a retrospective design, selection bias such as heterogenicity of chemotherapy regimens and duration could not be excluded completely. Second, the total number of patients was small, and the lack of standardization of clinical assays are an important problem. Third, some important pathological reports, such as perineural invasion, were not included in the study because they were not documented. Further well-designed prospective studies are needed. However, all patients involved were synchronously diagnosed and operated on for lesions of colon and liver; therefore, the biases were minimized.

In summary, elevated preoperative NLR is strongly correlated with both survival and recurrence in patients who have been diagnosed with resectable synchronous CRC with liver metastases. Combined NLR and CEA levels could be a more powerful prognostic marker than NLR alone. Preoperatively, measurement of NLR and CEA level may a provide simple method for identifying patients with a poorer prognosis in resectable sCRLM. Further it will allow optimization for selecting patients who will need further treatment, such as inflammatory and immune modulation, which could improve their long-term outcomes.

\section{CONFLICTS OF INTEREST}

No potential conflict of interest relevant to this article was reported.

\section{ACKNOWLEDGEMENTS}

This work was supported by the Soonchunhyang University Research Fund.

\section{REFERENCES}

1. Jung KW, Won YJ, Oh CM, Kong HJ, Lee $\mathrm{DH}$, Lee $\mathrm{KH}$, et al. Cancer statistics in Korea: incidence, mortality, survival, and prevalence in 2014. Cancer Res Treat 2017; 49:292-305.

2. Li Y, Bi X, Zhao J, Huang Z, Zhou J, Li Z, et al. Simultaneous hepatic resection benefits patients with synchronous colorectal cancer liver metastases. Chin J Cancer Res 2016;28:528-35.

3. Bertens KA, Hawel J, Lung K, Buac S, Pineda-Solis K, Hernandez-Alejandro R.
ALPPS: challenging the concept of unresectability--a systematic review. Int J Surg 2015;13:280-7.

4. Sandstrom P, Rosok BI, Sparrelid E, Larsen PN, Larsson AL, Lindell G, et al. ALPPS improves resectability ompared with conventional two-stage hepatectomy in patients with advanced colorectal liver metastasis: results from a Scandinavian Multicenter Randomized Controlled Trial (LIGRO Trial). Ann Surg 2018;267:833-40.

5. Ozyalvacli G, Yesil C, Kargi E, Kizildag B,
Kilitci A, Yilmaz F. Diagnostic and prognostic importance of the neutrophil lymphocyte ratio in breast cancer. Asian Pac J Cancer Prev 2014;15:10363-6.

6. el Aziz LM. Blood neutrophil-lymphocyte ratio predicts survival in locally advanced cancer stomach treated with neoadjuvant chemotherapy FOLFOX 4. Med Oncol 2014:31:311

7. Stotz M, Gerger A, Eisner F, Szkandera J, Loibner $\mathrm{H}$, Ress $\mathrm{AL}$, et al. Increased neutrophil-lymphocyte ratio is a poor prog- 
nostic factor in patients with primary operable and inoperable pancreatic cancer. Br J Cancer 2013;109:416-21.

8. Gomez D, Farid S, Malik HZ, Young AL, Toogood GJ, Lodge JP, et al. Preoperative neutrophil-to-lymphocyte ratio as a prognostic predictor after curative resection for hepatocellular carcinoma. World J Surg 2008:32:1757-62.

9. Walsh SR, Cook EJ, Goulder F, Justin TA, Keeling NJ. Neutrophil-lymphocyte ratio as a prognostic factor in colorectal cancer. J Surg Oncol 2005:91:181-4.

10. Tang H, Li B, Zhang A, Lu W, Xiang C, Dong J. Prognostic significance of neutrophil-to-lymphocyte ratio in colorectal liver metastasis: a systematic review and metaanalysis. PLoS One 2016;11:e0159447.

11. Bukowski J, Gozdz S, Sluszniak J, Kowalski D, Zagala A, Korejba W, et al. Carcinoembryonic antigen (CEA) in the serum of patients with cancer of the colon and rectum. Nowotwory 1986;36:181-6.

12. Albanopoulos K, Armakolas A, Konstadoulakis MM, Leandros E, Tsiompanou E, Katsaragakis S, et al. Prognostic significance of circulating antibodies against carcinoembryonic antigen (anti-CEA) in patients with colon cancer. Am J Gastroenterol. 2000 Apr;95(4):1056-61. Erratum in: Am J Gastroenterol 2009;104:2128.

13. Thomas P, Forse RA, Bajenova O. Carcinoembryonic antigen (CEA) and its receptor hnRNP M are mediators of metastasis and the inflammatory response in the liver. Clin Exp Metastasis 2011;28:923-32.

14. Pakdel A, Malekzadeh M, Naghibalhossaini $\mathrm{F}$. The association between preoperative serum CEA concentrations and synchronous liver metastasis in colorectal cancer patients. Cancer Biomark 2016;16:
245-52.

15. McNally GE, Lloyd DM, Grondona JP. Carcinoembryonic antigen as a prognostic factor in colorectal cancer with liver metastases. J Cancer Ther 2015;6:1035-44.

16. Halazun KJ, Aldoori A, Malik HZ, AlMukhtar A, Prasad KR, Toogood GJ, et al. Elevated preoperative neutrophil to lymphocyte ratio predicts survival following hepatic resection for colorectal liver metastases. Eur J Surg Oncol 2008;34:55-60.

17. Ding PR, An X, Zhang RX, Fang YJ, Li LR, Chen G, et al. Elevated preoperative neutrophil to lymphocyte ratio predicts risk of recurrence following curative resection for stage IIA colon cancer. Int J Colorectal Dis 2010;25:1427-33.

18. Chiang SF, Hung HY, Tang R, Changchien CR, Chen JS, You YT, et al. Can neutrophilto-lymphocyte ratio predict the survival of colorectal cancer patients who have received curative surgery electively? Int J Colorectal Dis 2012;27:1347-57.

19. Peng HX, Yang L, He BS, Pan YQ, Ying HQ, Sun HL, et al. Combination of preoperative NLR, PLR and CEA could increase the diagnostic efficacy for I-III stage CRC. J Clin Lab Anal 2017;31.

20. He W, Yin C, Guo G, Jiang C, Wang F, Qiu H, et al. Initial neutrophil lymphocyte ratio is superior to platelet lymphocyte ratio as an adverse prognostic and predictive factor in metastatic colorectal cancer. Med Oncol 2013;30:439.

21. Zhan X, Sun X, Hong Y, Wang Y, Ding K. Combined detection of preoperative neutrophil-to-lymphocyte ratio and CEA as an independent prognostic factor in nonmetastatic patients undergoing colorectal cancer resection is superior to NLR or CEA alone. Biomed Res Int 2017;2017:3809464.
22. Park MS, Yi NJ, Son SY, You T, Suh SW, Choi YR, et al. Histopathologic factors affecting tumor recurrence after hepatic resection in colorectal liver metastases. Ann Surg Treat Res 2014:87:14-21

23. Qian BZ. Inflammation fires up cancer metastasis. Semin Cancer Biol 2017;47: 170-6.

24. Kitamura T, Qian BZ, Pollard JW. Immune cell promotion of metastasis. Nat Rev Immunol 2015;15:73-86.

25. Grivennikov SI, Greten FR, Karin M. Immunity, inflammation, and cancer. Cell 2010;140:883-99.

26. Cools-Lartigue J, Spicer J, McDonald B, Gowing S, Chow S, Giannias B, et al. Neutrophil extracellular traps sequester circulating tumor cells and promote metastasis. J Clin Invest 2013. pii: 67484. doi: 10.1172/JCI67484.

27. Kemik O, Kemik AS, Sumer A, Begenik H, Purisa S, Tuzun S. Human neutrophil peptides 1, 2 and 3 (HNP 1-3): elevated serum levels in colorectal cancer and novel marker of lymphatic and hepatic metastasis. Hum Exp Toxicol 2013;32:167-71.

28. Wang D, Dubois RN. The role of COX-2 in intestinal inflammation and colorectal cancer. Oncogene 2010;29:781-8.

29. Goldstein MJ, Mitchell EP. Carcinoembryonic antigen in the staging and followup of patients with colorectal cancer. Cancer Invest 2005:23:338-51.

30. Schmoll HJ, Van Cutsem E, Stein A, Valentini V, Glimelius B, Haustermans $\mathrm{K}$, et al. ESMO Consensus Guidelines for management of patients with colon and rectal cancer. a personalized approach to clinical decision making. Ann Oncol 2012;23:2479-516 